Erratum

\title{
Erratum: Tsai, S.-L.; et al. The Coupled Photothermal Reaction and Transport in a Laser Additive Metal Nanolayer Simultaneous Synthesis and Pattering for Flexible Electronics. Nanomaterials 2016, 6, 12
}

\section{Nanoterials Editorial Office}

MDPI AG, Klybeckstrasse 64, CH-4057 Basel, Switzerland; nanomaterial@mdpi.com; Tel.: +41-61-683-77-34

Academic Editor: Thomas Nann

Received: 4 April 2016; Accepted: 7 April 2016; Published: 7 April 2016

Due to an error during production, the Figure $7 \mathrm{~b}$ in the published paper [1] was incorrect. The correct figure is as follows:

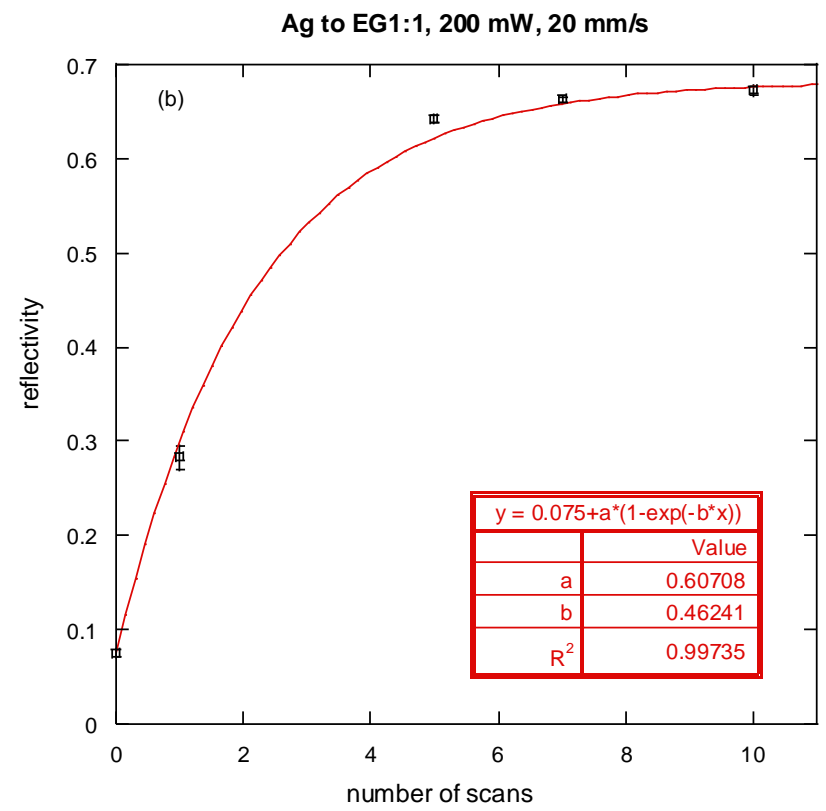

Figure 7. (a) Thickness of the silver film (b) reflectivity for $532 \mathrm{~nm}$ wavelength light versus number of laser scans (symbols: experimental data, lines: fitted curves).

We apologize for any inconvenience caused to readers or authors by these changes. The article will be updated and the original will remain available on the article webpage.

\section{Reference}

1. Tsai, S.-L.; Liu, Y.-K.; Pan, H.; Liu, C.-H.; Lee, M.-T. The coupled photothermal reaction and transport in a laser additive metal nanolayer simultaneous synthesis and pattering for flexible electronics. Nanomaterials 2016, 6, 12. [CrossRef]

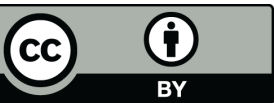

(C) 2016 by the author; licensee MDPI, Basel, Switzerland. This article is an open access article distributed under the terms and conditions of the Creative Commons by Attribution (CC-BY) license (http:/ / creativecommons.org/licenses/by/4.0/). 